\title{
An Analysis of Enterprise Value Growth: A Dynamic Equilibrium Model Based on Adaptive Innovation
}

\author{
- How to Build the Mechanism of Growth in the Enterprise Value on the Basis of Social Use Value
}

\author{
Bo Zhao", Xianglan Dong \\ Scientific Research Academy, Shanghai Maritime University, Shanghai, China \\ E-mail: "maimailmail@163.com,dxl0788@163.com \\ Received June 13, 2011; revised October 2, 2011; accepted October 9, 2011
}

\begin{abstract}
This paper combs the related knowledge of the social use value in supply from two aspects, adaptive behaveior and logic creative action. Then, the process of enterprise value growth is analyzed based on the circulation of adaptive behavior and the situation of logic creative behavior to break the long-run equilibrium, on the operation of which the paper shows the long-term equilibrium adjustment process from three procedures, and this is the dynamic process of enterprise overall value supply equilibrium. The next, new phenomenon in the dynamic equilibrium of enterprise value is further analyzed. In brief, the purpose of this paper is to build the mechanism of growth in the enterprise value on the basis of social use value.
\end{abstract}

Keywords: Adaptive Behavior, Logic Creative Action, Enterprise Value Growth, Substitution Effect, Residual Effect

\section{Introduction}

How to explain the fa'ct that enterprises can realize the non-physical balanced growth of the enterprise value which is difficult for the classical economics to explain too? Can we explain it from the goods, the value, the culture or human behavior? Naturally, in the history, the researches on the abstract theory of value studied by classical scholars have already been very perfect. However, they failed in offering practical guidance in the enterprises operating activities in the humane society [1]. How to create the enterprise value? How to run the enterprise value? How to expect the future growth of the enterprises value? And all of these questions have already been becoming more and more confused ones for scholars and practitioners in all economic and management fields.

\section{The Supply of Social Use Value: Adaptive Behavior \& Logic Creative Action}

\subsection{Adaptive Behavior}

\subsubsection{Adaptive Behavior and the Supply of Social Use Value}

Adaptive behavior is usually called the adaptive supply of social use value. Enterprises stimulate psychology and behavior of social actor to meet the demand of humanities and social values in two ways:

The first is that enterprises copy the humanistic values mode of social target groups; the second is that enterprises simulate the humanistic values mode of social target groups. Thus, enterprises shape and realize social use value of commodity through the two methods.

The requirements of the enterprises' adaptive commodity in supply:

First, the supply of enterprises' adaptive goods usually refers to the development and improvement of the goods which are in the same nature.

Second, enterprises should make adaptive adjustment according to value pattern of different target groups in different times.

Third, the enterprise overall value innovation is for the purpose of meeting the greatest utility of social actor in different stages. And the greatest utility of social actor is their price cognition representing the equivalent of their currency measure.

Fourth, the purpose of the enterprise adaptive behavior is to use the social use value of the goods to realize the greatest utility of the social actor's cognition to obtain the growing of enterprise value recognition, the essence of which is the sustainable growth of the enterprise over- 
all value.

Fifth, investment in the enterprise adaptive behavior is affected by the social actor's maximum value of goods.

\subsubsection{Theory of Adaptive Behavior}

Adaptive behavior is not to change the essential attribute of goods but to affect the value cognition and behavior of social actor though shaping the social use value of the goods.

The term, adaptation, comes from biology [2]. Michael Little used this word in biology application. Adaptation has two meanings: The first meaning refers to the feedback made by living creature in the environment which contributes to maintenance or improvement of community survival characters; the second meaning is the behavior of living creature to deal with the environment in life which works through the process of cognition and perception.

In the science of human behavior, adaptation is derived from the second meaning. This adaptive behavior has something to do with values and also the criteria in judgment in addition to the function of realizing living or meeting the demand. What's more, human values are associated with the expected results of human behavior. It is an innovative or creative response of human adaptive behavior. Besides, adaptation can be divided into "internal adaptation" (internal adaptation) and "external adaptation" (external adaptation). The behavior of human has adaptation in cultural behavior [3]. Anthropologists focus on the adaptive responses of individuals and groups in the cultural behavior. Cultural behavior is a patterned, shared and traditional behavior, which is also the unique characteristic of human.

Adaptive behavior for economic analysis is derived from "adaptive expectations" put forward by Milton Friedman known as a famous economist.

The meaning he expressed is that: people often modify their outlook on the future step by step in order to adapt to the changes of objective things [4].

\subsection{Logic Creative Behavior}

\subsubsection{Logic Creative Behavior \& the Social Value of New Commodity in the Supply}

Logic creative behavior is called as the development and supply of new commodity which Conforms to the social vision demand. Enterprises inspire people's psychologycal needs of new things through the analysis of human values' patterns in human society and logic creation in order to adapt to the trends of social value and the needs of social vision. In this way, enterprises create the social use value of goods in new field to meet the needs of hu- man society, and then realize the social use value of goods in supply.

Enterprises' logic behavior gets done through the alternative technological innovation (the alternative behavior) and straight-pilot technological innovation (pioneering behavior), which rely on advances in knowledge to cope with the trends of social and cultural value mode and social vision. This feature is reflected in two ways:

Firstly, upon the connotation of knowledge and technology connotation, the alternative behavior can replace many of the features of existing products, reflect the updated knowledge and advanced technology, meet lifestyle aspirations of the people, and also meet the objecttive requirements proposed by people in their thoughts technologically.

Secondly, during the progress of knowledge civilization in human society, the new areas of corporate strategic innovation are higher level demands of social development and quality of life. Thus, people need to develop a variety of new areas to broaden their vision and improve the material and spiritual life.

\subsubsection{Theory of Logic Creative Behavior}

Logic creative behavior as one of concepts in Behavioral Science has the nature of "innovative" in economics. Joseph Schumpeter used the word "Innovation" (Innovation) in the book "Theory of Economic Development," and this gradually formed the economic theory the core of which is innovation- "innovation" theory [5]. The symbol of successful innovation manifests in the three aspects: first, whether commercial value is obtained or not; Second, whether incremental growth is obtained or not, namely marginal growth; Third, whether the magnitude of irregular growth in the economic is gotten or not. R-Musser gave the explanation of abnormal growth: first, the unconventional activities, including novelty and non-continuity; second, activities must be to achieve ultimate success (Figure 1).

\section{The Process of Enterprise Value Growth: The Cycle of Enterprises' Adaptive Behavior and Logic Creative Behavior}

\subsection{The Circulation of Adaptive Behavior (Figures 2 and 3 )}

The circulation adaptive behavior is that companies improve the effectiveness of social actor's satisfaction by the way of the adaptive behavior in order to maintain the growing process of enterprise value after a period of social use value of goods completed. What's more, new areas which are developed successfully often bring so 


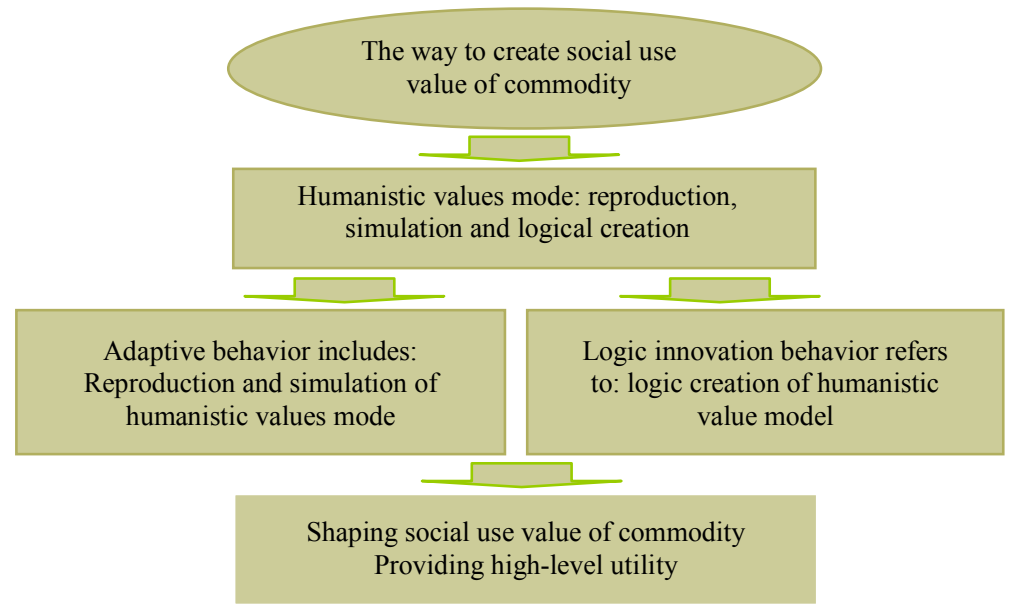

Figure 1. Logic figure of the social value use in supply.

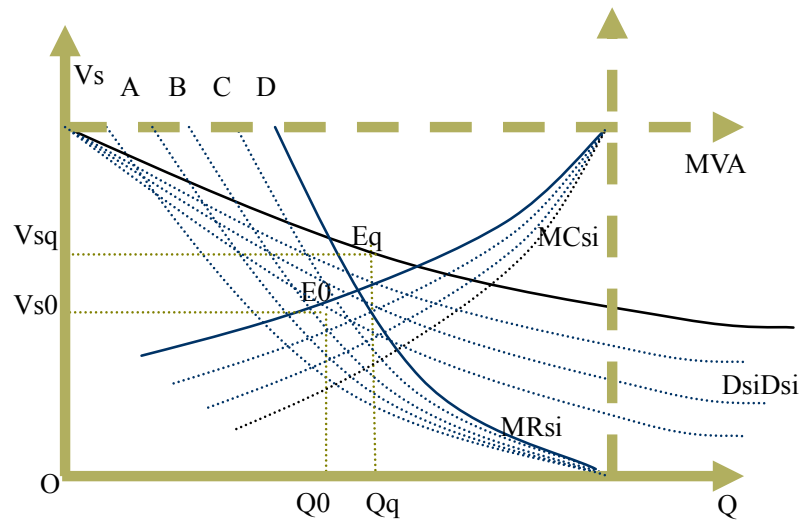

Figure 2. The circulation of adaptive behavior. (Description: according to the principle of marginal social cost MCsi equal with marginal social return MRsi, MCsi = MRsi, enterprises can expand the size, and also provide goods an increasingly).

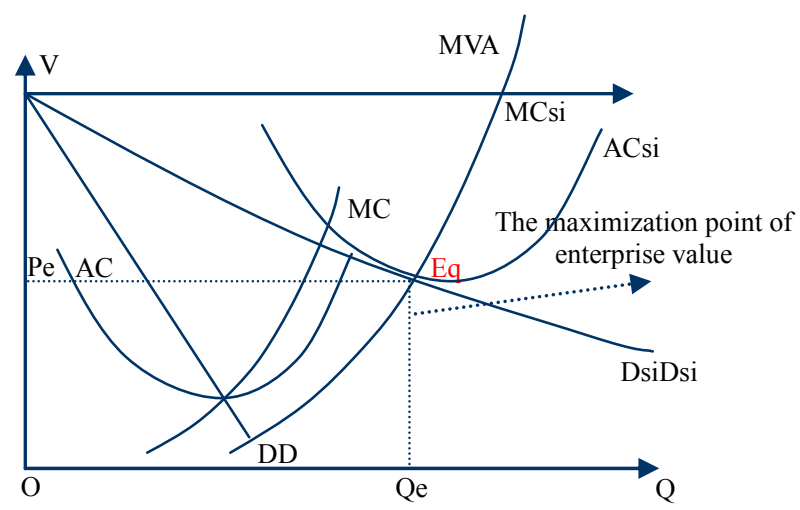

Figure 3. The case that enter value reaches extreme. (Description: when the average social return ARsi can reach the tangent point Eq of social use value of goods demand curve DsiDsi and average social cost curve ACsi, the company reach its maximum size $\mathrm{Qe}$ and equilibrium point $\mathrm{Eq}$ (Pe, Qe). Furthermore, this is the highest growth of enterprise value through adaptive behavior). tremendous income to the enterprise that they can attract competitors who imitate and produce the existing products to be the greatest obstacle to company competition. With the mature of technology and management, more and more competitors move into new areas to form the monopolistic competition situation gradually. In this case, the enterprise will improve the adaptability of the product in order to maintain their monopoly position. What's more, the enterprise can enrich the more content of human values gradually to stimulate consumers' motivation. And in this way, companies entered the circulation of adaptive behavior.

\subsection{The Possibility of Oligopoly Caused by Adaptive Behavior}

\subsubsection{The Possibility of Oligopoly}

Different enterprises adapt to different social groups and get certain loyalty, so it may bring in the oligopoly during in the process of enterprises' adaptive behavior cycle. The adaptive behavior is based on the model of mining the target group value in order to attract group attention. The social actor has relative stability about the signifycance of human values, so it can make enterprise get certain loyalty from the social actor. And this situation often leads to oligopoly.

\subsubsection{The Existing Situation of Oligopoly Is Different from Traditional}

The existing situation of oligopoly is different from traditional forms such as Augustin Cournot, John Chamberlain, Swift and other oligopoly which has collusion. This kind of market structure is based on cost advantage, economies of scale, capital advantages or joint union. In the contemporary era, capital and economies of scale are not the obstacles for an industry. Oligopoly can only be formed on the basis of getting value cognition from a 
range of social groups. And this value exists in subjecttive world. Whichever enterprise is better able to shape the meaning of human values to meet the higher needs of social actors and get the value of knowledge, it can get extensive social consumer groups. And only in this way can market structure of oligopoly keep.

\subsubsection{The Unstable Trend of Existence}

In the information age, due to low-cost information dissemination, it is relatively easy to conduct the development model, production model, management model of any enterprise. On the other hand, it is not difficult for enterprises to disseminate the significance of humanities value to set up the enterprise image. In addition, the information age changes values and lifestyle of people quickly. Because of the capital abundance in the knowledge economy stage, capital is not a barrier for the industry to enter into the various modes operation. The fact that capital chases knowledge causes enterprises to excavate social humanistic value from many different aspects and reflect out in the possible way. And they compete fiercely in the traditional industry, and then the saturation state is formed. And this is the unstable stage of oligopoly. Finally, oligarchic monopoly is finally replaced by monopolistic competition due to the update of the enterprise' difference and diversification. Besides, knowledge economy is carried out in fast innovation, and monopoly is not a relatively stable form. In fact, each enterprise which can achieve innovation rapidly can get preconceived market position. Therefore, the human innovation will be an important part in the operation of the enterprise overall value and enterprise value.

\subsection{The Situation of Logic Creative Behavior to Break the Long-Run Equilibrium}

Logic creative behavior is looking for the social needs.
And this can often help enterprises win the competition in absolute monopoly. Especially in the knowledge economy era, knowledge is updated so fast that new products continuously get developed and produced. But not all the new things have a realistic demand or current social value. The human innovation what we refer to is to obtain the cognition of human social value mode and can bring in creative activities to achieve social use value of goods.

Human innovation is often the starting point to break the long-run equilibrium. The activities of human innovation develop alternative field or new fields to form its own extensive value cognitive group, and promote the realization of commodities' social use value. However, human innovation must meet the cognition of social and cultural values first. But it is different to change the cognition of humanistic values. Therefore, enterprises are very easy to create loyalty groups to establish the position of absolute monopoly (Figure 4).

\section{Enterprise Value Growth Operation- Long-Term Equilibrium Adjustment Process}

\subsection{The Adjustment Process of Short-Term Equilibrium to Long-Term Equilibrium}

In the operation of enterprise overall value, enterprises get the space to adjust production. And the relationship between supply and demand is reflected in several procedures as followed:

\subsubsection{The First Procedure: Short-Term Equilibrium in Supply (Figure 5, "Diagram 1")}

First, in monopolistic competition market, enterprise's original intention is to organize production under the marginal principle, that is $\mathrm{MCs}=\mathrm{MRs}$, and provide the

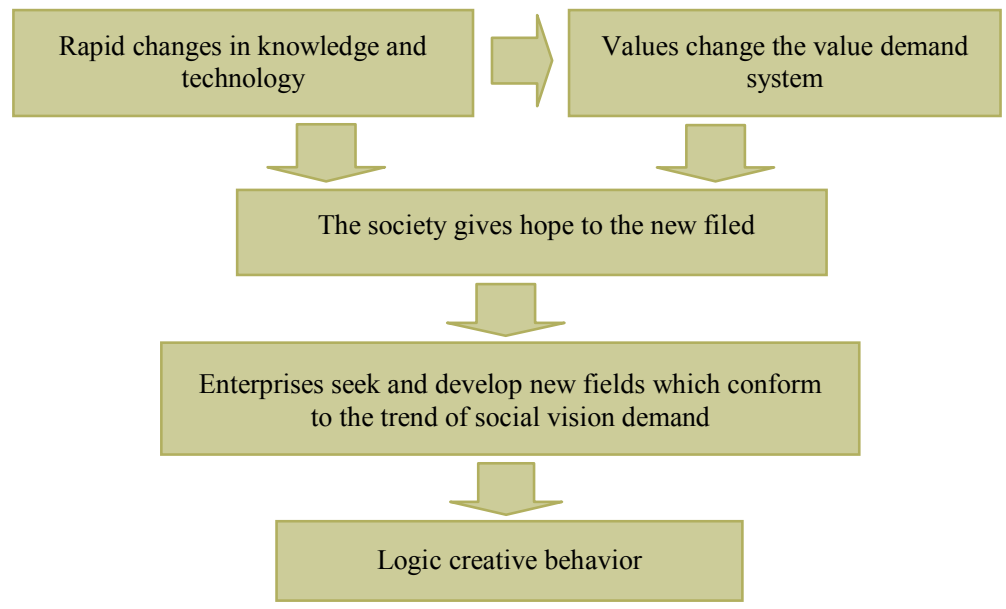

Figure 4. The forming process of logic creative behavior. 
goods.

Second, the enterprise has to face with two curves, expected returns curve ARs and social use value demand curve DsDs. The enterprise's production quantity is decided by expected returns curve ARs, while market price is decided by social use value demand curve DsDs.

Third, as new companies implement enterprise overall value production, each enterprise is likely to adjust ARs curve to the ARs' to determine the new output and price. Due to the existence of surplus, all enterprises make several adjustments to ultimately reach the equilibrium point $E$ at the intersection of DsDs and ARs which is also with the intersection of MRs and MCs in the same vertical line. In this way, enterprises can get the equilibrium output and equilibrium price.

Four, under the constraint of social use value demand curve, average social return of enterprises and social use value demand curve intersect at the point $\mathrm{E}$ which is the production and supply equilibrium expressed as (Q0, $\mathrm{P} 0)$. Marginal social cost curve MCs and marginal social return curve MRs intersect at E0; Marginal social cost curve and marginal social benefit MCs MRs curves intersect at E0; the point of intersection of the vertical line from $\mathrm{E}$ and the ACs is $\mathrm{F}$ which is the optimal cost of production expressed as NQ0.

Five, in the short term, enterprise excess profit is: $\mathrm{P} 0$ Q0 - NQ0.

\subsubsection{The Second Procedure: Long-Term Equilibrium in Supply (Figure 5, “Diagram 2”)}

First, the fact that some humanistic value models have characteristics in common can make other companies to copy and imitate information easily. In the end, a large number of companies can be much easier to operate production activities which have already owned their humanistic value models. As the enterprise can obtain monopoly profits in the production of social use value, it attracts other companies to integrate humanistic value into production of goods, which leads to increase the supply of social use value.

Second, we believe ideally that it is possible to the structure of perfect competition between a large number of enterprises, if humanistic value models can be copied and imitated solely. But humanistic values are diversified in the objective society so that this possibility is almost zero.

Third, the more enterprises join in, the more commodities are offered. The curves, short-term average cost curve and short-term marginal cost curve, move to the upper left gradually.

Four, long-run average cost curve LACs and longterm marginal cost curves LMC intersect at the equilib- rium point $\mathrm{E}$. Besides the social use value curve DsDs is also through equilibrium point E. What's more, the point $\mathrm{E}$ is market supply and demand equilibrium of the goods with the social use value.

\subsection{Long-Term Equilibrium of Social Use Value in Supply}

First, the optimum yield trend. As the enterprise can obtain monopoly profits in the production of social use value, it attracts other companies to integrate humanistic value into production of goods, which leads to increase the supply of social use value. In the long term, any enterprise which implements enterprise overall value production can be based on need to adjust the production scale to make output more or less under the effect of the social use value demand curve in the market. So enterprises can use established production scale to produce the optimum yield. Conversely, they can also have the optimum production scale under a given output level. In western economics, it is called the optimum yield using the most appropriate production scale. In a word, it reflects the optimum yield trend in process of the longterm enterprise overall value operation [6].

Second, analyze the trend of long-term lowest total cost. In the long process, all enterprises do not adjust investment and the scale of production ceaselessly based on the social use value demand until they adjust to the most moderate degree. Thus, due to the role of social use value supply-demand mechanism in the long term, no matter what kind of production any enterprise produces under the equal cost of production.

Third, avoid fully competition. We can't recognize market clearly according to the market price mechanism on humanity hypothesis so that enterprises cannot get a massive growth through enterprise overall value adaptability production. Comparing with other firms, these enterprises can receive additional return.

In Diagram 2, as enterprises enter and adjust the scale of production constantly, the long-term balance is formed, and the equilibrium point reaches at E0. Objectively, this long-run equilibrium state of perfect competition does not exist. In fact, enterprises have been engaged in monopolistic competition after entering. Besides supplied quantity Qi decided by corporate equilibrium quantity supplied Ei in the whole market is always on the left of Qi which is determined by the optimal configuration supply resources equilibrium point E0.

This state is the ideal perfectly competitive market structure in the formation process. However, different enterprises update and enrich the content of humanities and social value. Objectively this ideal state is impossible. 
The Third Procedure: Enterprise Overall Value

\section{Return (Figure 5, “Diagram 3")}

First, in fact, enterprises with the enterprise overall value have absolute monopoly in the market through brand effect and constant innovation of high technology. In the Diagram 3, every monopoly enterprise decides its equilibrium output Qi with marginal social cost and marginal social benefits Qi. The equilibrium point E0 decides the maximum yield point $\mathrm{Q} 0$, and the return of enterprise is zero under the production scale of $\mathrm{Q} 0$. So, enterprises produce effectively on the left of Q0, while loss on the right.

Second, on the left side of the equilibrium point E0, the process of innovation in enterprise overall value is embodied in the moving of the Mrsi curve which is constrained by Contour constraint line.

Third, According to innovation in enterprise overall value, graphics move MRsi curves constantly to the right. So these curves can intersect with MCi ceaselessly and reflect MRs1 curve, MRs2 curve, MRs3 curve, $\cdots$, MRsi curve and so on. Besides, MRsi curves intersect with $\mathrm{MC} 1$ curve, $\mathrm{MC} 2$ curve, $\mathrm{MC} 3$ curve, $\cdots, \mathrm{MCi}$ curve and so on at series of equilibrium points such as e1, e2, e3,, , ei.

Four, different points decided different equilibrium points to get the equilibrium quantities and prices, expressed as E1 (P1, Q1), E2 (P2, Q2), E3 (P3, Q3), Ei (Pi, Qi).

Five, we can see equilibrium quantity Qi is moving to the right. Besides, areas are also gradually increasing. What's more, this can explain earnings increase gradually, such as P1Q2, P2Q3, $\cdots$, PiQi.

In a word, enterprises' earnings are growing under along with the enterprise under the cycle of adaptive behavior.

The comparison of relationship between functions:

Diagram 1: Short-term monopoly profits of enterprises implementing the enterprise overall value:

Excess profit of the enterprise in the short term is: $\mathrm{P} 0$ Q0 - NQ0.

Conclusion: the first enterprise which implements of the enterprise overall value can get excess monopoly profits.

Diagram 2: The long-term equilibrium after the entrance of enterprises implementing the enterprise overall value

New equilibrium: $\mathrm{LAC}=\mathrm{LMC}=\mathrm{LARs}$

Conclusion: when the competition enterprises implementing the enterprise overall value reaches E, the supply and demand of the commodity are in equilibrium.

Diagram 3: Enterprise return can continue to grow through the adjustment of adaptive behavior in the long term.

Growth of return: PiQi $-\mathrm{P}(\mathrm{i}-1) \mathrm{Q}(\mathrm{i}-1)$
Accumulation of return: $\sum(\mathrm{PiQi}-\mathrm{P}(\mathrm{i}-1) \mathrm{Q}(\mathrm{i}-1))$

Conclusion: enterprise implementing the enterprise overall value can get the increasing return through adaptive behavior before the equilibrium point Ei which is called as the critical point of production and innovation.

\section{New Phenomenon in the Dynamic Equilibrium of Enterprise Value}

\subsection{The Substitution Effect of Social Use Value Demand Curve}

\subsubsection{Traditional Demand Curve}

In fact, enterprises which have the enterprise overall value of production activities are faced with the social use value demand curve DsDs. Because enterprises' behavior in market is not completely rational, they can only pay attention to the market prices which are reflected through market signals, and then affect their production activities. At first, they cannot make directly elastic reflection about the social use value demand. Therefore, enterprises decide their production in accordance with the principle of marginal optimal principle, that is $\mathrm{MR}=$ $\mathrm{MC}$ production, and make the market demand curve as the production premises of expected profits.

\subsubsection{Formation of the Social Use Value Demand Curve}

With the increase of social income and Merchandise competition, entrepreneurs begin to exert his or her subjectivity to tap the potential content of social and cultural value to get the information of social actors' potential needs which are not guided by the market price mechanism.

\subsubsection{The Substitution Effect of Social Use Value Demand Curve}

Along with the enterprise overall value activities started, production of goods excite social actor's attention to the social use value of goods. Thus, social actor's purchase behavior can form the social use value demand curve. Furthermore, what enterprise activities actual face with is not the market demand curve but the social use value demand curve.

\subsection{Enterprise Maximum Value Anticipation and Its Critical Point}

\subsubsection{Maximum Value Anticipation}

Maximum value anticipation lies in the place where the society use value production of commodity get the biggest output. In fact, any enterprise has two demand curves, 
Market demand curve DD and Social use value demand curve DsDs. But enterprises implementing enterprise overall value production always get more benefit than other enterprises. As enterprises compete in enterprise overall value production, the social use value demand curve DsDs plays its role. During that time, the maximum of enterprise production scale exceeds Qe1 which is decided by the long-term average social cost curve (LACs curve) and demand curve (DD curve). So the biggest output of enterprise production scale can move to the point $\mathrm{e} 0$ which is decided by long-term average social cost curve (LACs curve) and social use value demand curve(DsDs curve) (Figure 5).

\subsubsection{Critical Point E0}

Along with the enterprise overall value creation activities, enterprises innovate the content of humanistic value in products so as to raise the social use value. To achieve this aim, enterprises not only enlarge production scale but also raise the cost. But when the cost is equal to the value of the intersection decided by LACs curve and DsDs curve, enterprises will no longer grant any additional monopoly profits. That point is called as critical point $\mathrm{E} 0$ ( $\mathrm{P} 0, \mathrm{Q} 0)$ of the enterprise overall value production activities (Figure 5).

\subsection{The Residual Effect of Social Use Value}

\subsubsection{Social Use Value of Producer Surplus [7]}

Social use value of producer surplus is that enterprise overall value production activities make social use value demand curve replaced market demand curve, because of which enterprise production competitive equilibrium is changed by E1 transferred to E0, and then the entire market drives the supply of commodity because of the increasing demand of social use value, meanwhile the market prices of commodities' society use value are improved. At the same time, because enterprise behavior isn't entirely rational but limited rational, the expected equilibrium of enterprise overall value production is determined in E1 on the basic of that the output and price of equilibrium are decided by market demand curve. Thus the output and price of equilibrium are low to these decided by social use price to make enterprises gain unexpected earnings. And it is this situation that we call enterprise overall value of producer surplus effect.

Enterprise overall value surplus is the extra income which is over material products value in value realization process. Enterprise overall value of producer surplus is expressed as: $\mathrm{Qe} 0 \mathrm{Pe} 0$ - Qe1Pe', which is the excess profits gained by enterprise overall value production and formed by accumulation of excess profits in enterprise overall value (Figure 6).

\subsubsection{Social Use Value of Consumer Surplus [6]}

In the production of material products, enterprises integrate concepts of value with humanistic ideas and other spiritual form so as to increase the effectiveness of the consumers' satisfied degree. On one hand, they need to attract attention to promote the realization of social actors' payment. On the other hand, enterprises make their initial price on the basis of the market demand curve but not the social use value demand curve for the sake of a higher social use value at a lower price. At the same time, social actors can receive extra utility satisfaction more than the concrete usefulness from the goods and services. So we call the situation that Social actors obtain higher value with less money as social use value of consumer surplus effect. Social use value of consumer surplus effect is a starting point which can make enterprises to raise commodity prices continuously and to turn benefit on the basis of market price into that on the basis of social use value. But consumer surplus will gradually disappear along with commodity prices increased gradually which can also keep consumers [6].

\subsubsection{The Effect of Expected Value Added}

Enterprises get the maximum supply quantity in accordance with marginal principle. But enterprise decision makers decide price in accordance with natural use value of goods in market because of the irrational expectations [8]. Thus social actors can get the consumer surplus from that price. So enterprises meet equivalent earnings increase will achieve the effect of expected value added. When business income is equal to consumers' utility satisfaction of social use value, enterprise will get the expected earnings increased effect which includes two parts, the added effect of quantity supplied and increased prices effect.

\subsubsection{Interpretation}

First, because the equilibrium is located in E0 under completely competitive market, benefit of any enterprise in E0 is zero. In other words, enterprise is likely to lose money on the right of that point.

Second, in the equilibrium, society use value curve DsDs play their regulatory requirements role, while DD curve are no longer to regulate society use value demand. Thus, enterprises get the highest average cost and the highest income in the equilibrium. Besides the output at that point is Q0, while market price of social use value is $\mathrm{Pe} 0$.

Third, the limited rational expectations of the enterprise are made according to the market demand curve. At this time, expected output is Qe1, and expected price is $\mathrm{Pe}^{\prime}$, and cost of production is Pe1. But actually, enterprise is confronted with social use value demand curve. 


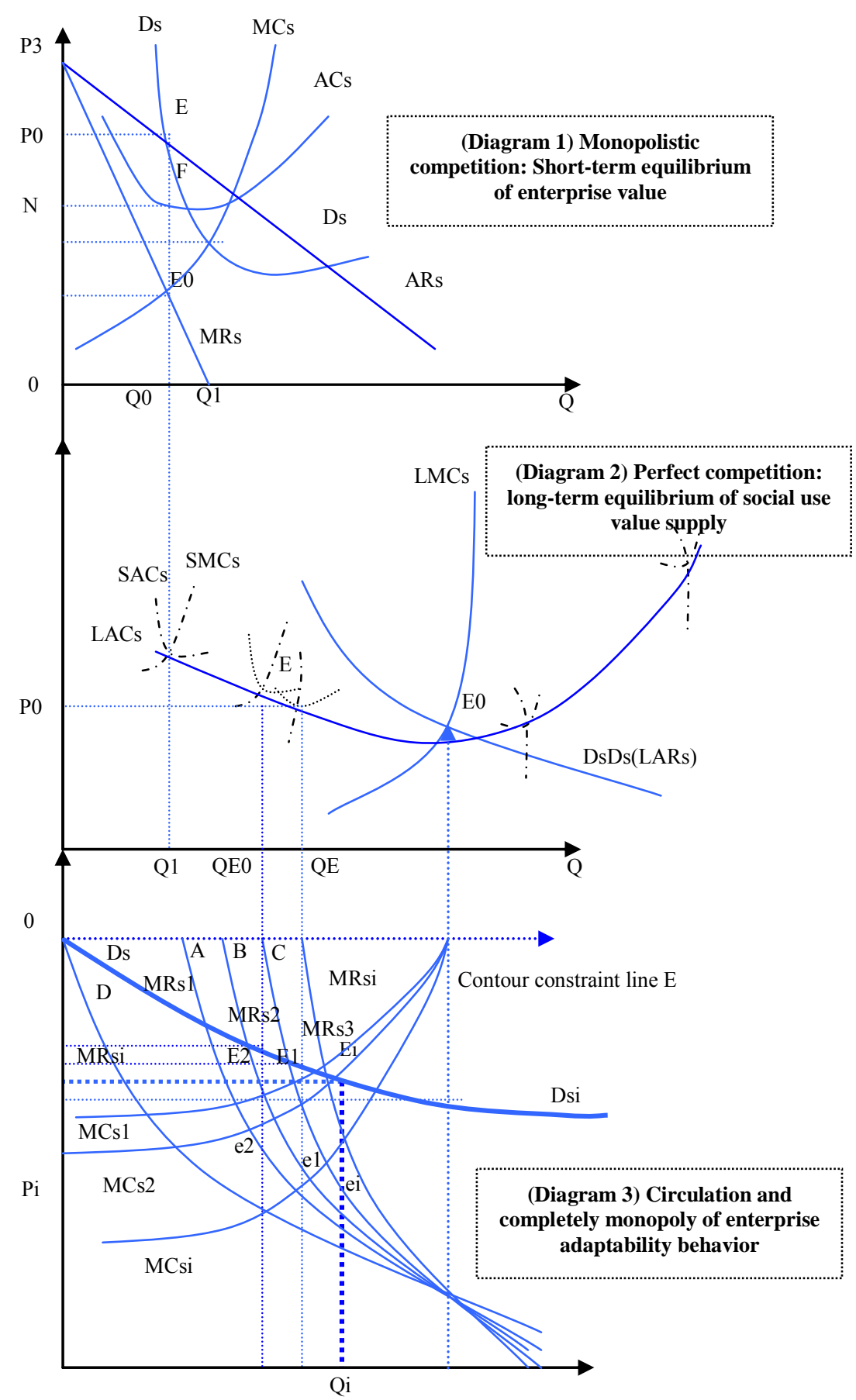

Figure 5. The long-term adjustment process of social use value production. (Diagram 1: DsDs curve: Social use value demand curve. ARs curve: Enterprise average social return curve; Expected social use value demand curve of individual enterprise; ARs' curve: Enterprise adjusted average social return curve; Adjusted expected social use value demand curve of individual enterprise. MRs curve: Marginal social return curve; MCs curve: Marginal social cost curve; E(Q0, P0) point: Production point of short-term equilibrium. Diagram 2: SACs curve: Enterprise's short-term average social cost curve. SMCs curve: Enterprise's short-term marginal social cost curve; LACs curve: Long-term average social cost curve; LMCs curve: Long-term marginal social cost curve; DsDs curve (LARs): Social demand curve with which social use value of enterprise products face. Diagram 3: MRs1 curve: Marginal social use value curve 1. MRs2 curve: Marginal social use value curve 2; MRs3 curve: Marginal social use value curve 3; MRsi curve: Marginal social use value curve i; MCsi curve: Marginal social cost curve i; MCs1 curve: Marginal social cost curve 1; MCs2 curve: Marginal social cost curve 2; MCs3curve: Marginal social cost curve 3; A.B.C.E lines: Contour constraint lines). 


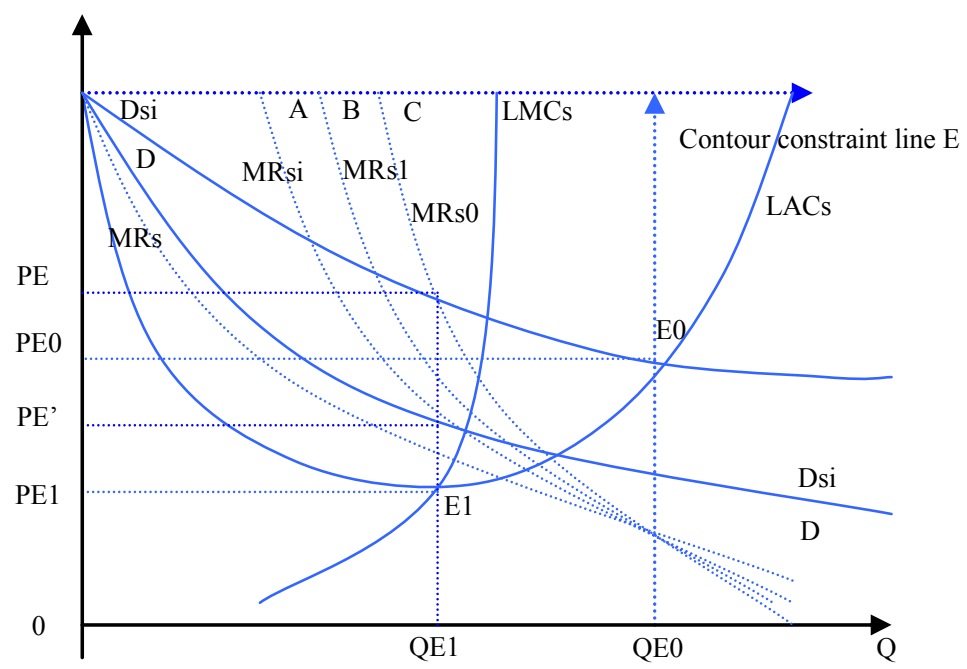

Figure 6. Critical point and the maximum yield of social value production costs. MRs1 curve: Marginal social use value curve 1; MRs2 curve: Marginal social use value curve 2; MRsi curve: Marginal social use value curve i; LMCs curve: Long-term marginal cost curve; LACs curve: Long-run average cost curve; A.B.C.E lines: Contour constraint lines.

So the actual maximum production of the equilibrium is $\mathrm{E} 0$, and the actual biggest output is Q0, and the actual highest price is $\mathrm{P} 0$.

Four, enterprise overall value benefit is $\mathrm{Qe} 0 \times \mathrm{Pe} 0$ on the left of equilibrium E0, while enterprise overall value surplus is Qe $0 \mathrm{Pe} 0-\mathrm{Qe} 1 \mathrm{Pe}$.

\section{Conclusions}

Although companies can influence the social use value of goods in supply through the behavior initiative, and affect the achievement of the usefulness of the commodities' value in the recognition of human values, the root cause of enterprises to increase their value is that the operation of commodities' social use value can promote the functioning of commodity value in the effective way. Besides we can make a classification of corporate behavior: the one is the adaptive behavior which is not to change the essential attribute of goods but to copy and simulate the humanistic values mode to enrich the connotation of commodities in their social use value; the other one is the logical innovation behavior which is that the enterprises encourage innovation about the new products which are consistent with the social vision through creating the humanistic values mode logically, then explore new territory. As the social actors' cognition of maximum effectiveness brought by commodities is imitated by the essential nature of commodities, companies need to increase and improve the social actors' effectiveness brought by the social use value of goods through the adaptive behavior continually, but this effectiveness is also limited. If this limit constraint is reached, the enterprise value will also reach its limit. Thus, companies have to develop innovation in new areas. In a word, it is the virtuous cycle of the adaptive behavior and the logical innovation behavior that is the operation mechanism in the growth of enterprise value.

\section{References}

[1] B. Zhao, "A Study on Renwen Value: The Principle of Value Running and the Mechanism of the Growth of Enterprise Value," Liaoning People's Publishing House, Liaoning, 2005.

[2] S. Y. Ding, "Ecology: Face to Scientific Value of the Human Environment," Scientific and Technical Publishers, Shanghai, 2003.

[3] C. Kluckhohn, "The Study of Culture," Zhejiang People's Publishing House, Hangzhou, 1996.

[4] M. Friedman, "Competition and Monopoly," Shanxi People's Publishing House, Xi'an, 1994.

[5] J. Schumpeter, "Capitalism, Socialism and Democracy," Commercial Press, Beijing, 1985.

[6] P. Samuelson and W. D. Nordhaus, "Microeconomics," 16th Edition, Mcgraw Hill Press, Beijing, 1999.

[7] A. Marshall, "The Economics Principle," The Commercial Press, Beijing, 1976.

[8] R. J. Shiller, "Irrational Exuberance," China Renmin University Press, Beijing, 2001. 